\title{
History or demography? Determining the drivers of genetic variation in North American plants
}

\author{
Julia López-Delgado ${ }^{1}$ and Patrick Meirmans ${ }^{2}$ \\ ${ }^{1}$ University of Leeds Faculty of Biological Sciences \\ ${ }^{2}$ University of Amsterdam Institute for Biodiversity and Ecosystem Dynamics
}

August 18, 2020

\begin{abstract}
Understanding the impact of historical and demographic processes on genetic variation is essential for devising conservation strategies and predicting responses to climate change. Recolonizations after Pleistocene glaciations and population's positions within species ranges are expected to leave distinct genetic signatures. However, the general applicability of these patterns and relative importance of historical and demographic factors remains unknown. Here, we analysed the distribution of genetic variation in 91 native species of North American plants by coupling microsatellite data and Species Distribution Modelling. We tested the contributions of historical climatic shifts and the central-marginal hypothesis on genetic diversity and structure. Decreased diversity was found with increased distance from potential glacial refugia, coinciding with the expected makeup of postglacially colonised localities. At the range periphery, lower genetic diversity, higher inbreeding levels and genetic differentiation were reported, following the assumptions of the central-marginal hypothesis. History and demography were found to have approximately equal importance in shaping genetic variation.
\end{abstract}

\section{Hosted file}

EcolLett_Manuscript_Lopez-Delgado_Meirmans.pdf available at https://authorea.com/users/ 305209/articles/476391-history-or-demography-determining-the-drivers-of-genetic-

variation-in-north-american-plants 